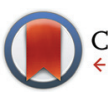

CrossMark

Cite this: Org. Biomol. Chem., 2015, 13,223

Received 11th August 2014, Accepted 29th October 2014 DOI: $10.1039 / c 40 b 02282 c$ www.rsc.org/obc

\section{Systematic methodology for the development of biocatalytic hydrogen-borrowing cascades: application to the synthesis of chiral $\alpha$-substituted carboxylic acids from $\alpha$-substituted $\boldsymbol{\alpha}, \boldsymbol{\beta}$-unsaturated aldehydes $\uparrow$}

\author{
Tanja Knaus, $\neq^{\mathrm{a}}$ Francesco G. Mutti, $\dot{t}^{\mathrm{b}}$ Luke D. Humphreys, ${ }^{\mathrm{c}}$ Nicholas J. Turner ${ }^{\mathrm{b}}$ and \\ Nigel S. Scrutton*a
}

\begin{abstract}
Ene-reductases (ERs) are flavin dependent enzymes that catalyze the asymmetric reduction of activated carbon-carbon double bonds. In particular, $\alpha, \beta$-unsaturated carbonyl compounds (e.g. enals and enones) as well as nitroalkenes are rapidly reduced. Conversely, $\alpha, \beta$-unsaturated esters are poorly accepted substrates whereas free carboxylic acids are not converted at all. The only exceptions are $\alpha, \beta$-unsaturated diacids, diesters as well as esters bearing an electron-withdrawing group in $\alpha$ - or $\beta$-position. Here, we present an alternative approach that has a general applicability for directly obtaining diverse chiral $\alpha$-substituted carboxylic acids. This approach combines two enzyme classes, namely ERs and aldehyde dehydrogenases (Ald-DHs), in a concurrent reductive-oxidative biocatalytic cascade. This strategy has several advantages as the starting material is an $\alpha$-substituted $\alpha, \beta$-unsaturated aldehyde, a class of compounds extremely reactive for the reduction of the alkene moiety. Furthermore no external hydride source from a sacrificial substrate (e.g. glucose, formate) is required since the hydride for the first reductive step is liberated in the second oxidative step. Such a process is defined as a hydrogen-borrowing cascade. This methodology has wide applicability as it was successfully applied to the synthesis of chiral substituted hydrocinnamic acids, aliphatic acids, heterocycles and even acetylated amino acids with elevated yield, chemo- and stereo-selectivity. A systematic methodology for optimizing the hydrogen-borrowing twoenzyme synthesis of $\alpha$-chiral substituted carboxylic acids was developed. This systematic methodology has general applicability for the development of diverse hydrogen-borrowing processes that possess the highest atom efficiency and the lowest environmental impact.
\end{abstract}

\section{Introduction}

Nowadays, there is an urgent demand for new chemical reactions and processes that possess an elevated atom efficiency as well as a low environmental impact. ${ }^{1-3}$ Multi-step chemical

\footnotetext{
${ }^{a}$ Manchester Institute of Biotechnology, Faculty of Life Sciences, University of Manchester, 131 Princess Street, Manchester, M1 TDN, UK.

E-mail: nigel.scrutton@manchester.ac.uk

${ }^{b}$ Manchester Institute of Biotechnology, School of Chemistry, University of

Manchester, 131 Princess Street, Manchester, M1 $7 D N$, UK

'GSK Medicines Research Centre, Gunnel's Wood Road, Stevenage, Herts, $S G 12 N Y, U K$

$\dagger$ Electronic supplementary information (ESI) available: Synthesis of substrates and reference compounds, sources and cloning/expression/purification conditions for ERs and Ald-DHs used in this study, analytical methods as well as chiral GC and HPLC chromatograms. See DOI: 10.1039/c4ob02282c

$\$$ These authors contributed equally to this work.
}

reactions using enzymes one pot allow this goal to be achieved as intermediate isolation and purification steps are avoided and energy consumption is minimized. ${ }^{4,5}$ The major challenge is to perform cascade reactions wherein an oxidative and a reductive step are running simultaneously without any compartmentalization. ${ }^{6}$ One of the early examples of two-step concurrent oxidative-reductive enzymatic cascades was the deracemization and the stereoinversion of secondary alcohols using stereocomplementary alcohol dehydrogenases (ADHs). ${ }^{7}$ However, this cascade was operated by four enzymes constituting two redox independent steps (i.e. non-interconnected); as a consequence, redox equivalents were supplied at the expense of formate and molecular oxygen as sacrificial co-substrates, hence generating hydrogen peroxide and carbon dioxide as waste. A similar concept was applied to the two-step oxidativereductive combination of an enzyme with an artificial metalenzyme or a metal catalyst. ${ }^{8,9}$ In contrast, a two-step redox 
self-sufficient biocatalytic network has been recently presented for the amination of primary alcohols. ${ }^{10}$ In this case, the redox equivalents liberated in the first oxidative step were consumed in the second reductive step in the form of $\mathrm{NAD}(\mathrm{P}) \mathrm{H}$. As the cofactor acts as a shuttle of hydride within the catalytic cycle, such a process is also defined as a hydrogen-borrowing cascade. Another example is biocatalytic redox isomerisation of allylic alcohols. ${ }^{11}$ Recently, a hydrogen-borrowing biocatalytic synthesis of $\alpha$-substituted carboxylic acids from $\alpha$-substituted $\alpha, \beta$-unsaturated aldehydes was presented. ${ }^{12}$ However, the two-step cascade was run using crude preparations of the enzymes (cell extracts) and thereby efficient internal recycling of the nicotinamide cofactor was not demonstrated as other enzymes may contribute to the overall process. Furthermore, a general strategy for setting up a hydrogen-borrowing biocatalytic cascade has not been presented until to date. Thus, in this work, we decided to study a systematic approach for developing a successful biocatalytic hydrogen-borrowing cascade. The asymmetric hydrogen-borrowing biocatalytic synthesis of $\alpha$-substituted carboxylic acids from $\alpha$-substituted $\alpha, \beta$-unsaturated aldehydes was chosen as the case study. The development of such a cascade is not trivial since the enzymes involved in the reductive and in the oxidative steps have to operate concomitantly with high activity and stability, and under the same reaction conditions $(T, \mathrm{pH}$, type of cofactor, type of buffer, cosolvent, etc.). Moreover, enzyme concentrations and kinetics have to be thoroughly studied in order to maximize chemo- and stereoselectivity.

Ene-reductases (ERs) from the "Old Yellow Enzyme Family" (OYEs) are flavin dependent enzymes that, in the last decade, have been applied extensively in biocatalysis. ${ }^{13-16}$ These enzymes catalyze the asymmetric reduction of carbon-carbon double bonds that are activated by conjugation with an electron-withdrawing substituent. In particular, $\alpha, \beta$-unsaturated carbonylic compounds (e.g. enals and enones) as well as nitroalkenes are rapidly reduced by the ERs, affording quantitative yields in most cases. ${ }^{17,18,19-22}$ In contrast, alkenes bearing a single conjugated ester moiety or a free carboxylic group are poorly reduced or not converted at all. ${ }^{23-25}$ Reduction of acid derivatives is restricted to only a few families such as $\alpha, \beta$-unsaturated, 1-2 substituted diesters or diacids (e.g. fumarate, maleate, citraconate, mesaconate) or $\beta$-cyano-, $\beta$-alkoxy- and $\beta$-aryloxy- $\alpha, \beta$-unsaturated esters. ${ }^{26-30}$ More recently, it has been shown that an electron-withdrawing halogen group in the $\alpha$-position can significantly increase the reactivity of $\alpha, \beta$-unsaturated esters towards bio-reduction. ${ }^{31-33}$ The requirement of an additional activating group, significantly narrows the substrate scope for the biocatalytic asymmetric reduction of $\alpha, \beta$-unsaturated esters, whereas the same reaction on $\alpha, \beta$-unsaturated acids is completely inapplicable. This is a potential limitation given that most developed synthetic routes to pharmaceuticals and agrochemicals require optically active $\alpha$-substituted carboxylic acids as intermediates. Therefore, synthetic routes involving an ER would require a further hydrolytic step to obtain the carboxylic moiety from the related ester. Crucially, the direct reduction of activated

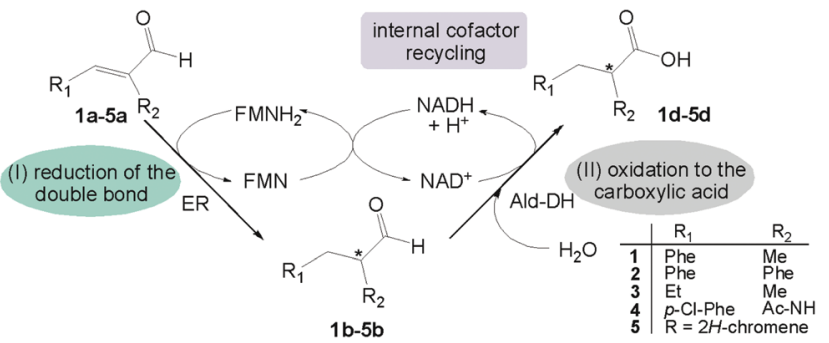

Scheme 1 Concurrent redox self-sufficient two enzyme cascade reaction. The redox equivalents required in the first reductive step are provided by the second oxidative step in form of $\mathrm{NAD}(\mathrm{P}) \mathrm{H}$.

$\alpha, \beta$-unsaturated esters requires an external source of hydride that is provided by the $\mathrm{NAD}(\mathrm{P}) \mathrm{H}$ cofactor. Most of the recent publications report the reduction of activated $\alpha, \beta$-unsaturated esters using suprastoichiometric NAD(P)H or catalytic $\mathrm{NAD}(\mathrm{P}) \mathrm{H}$ in presence of glucose as the sacrificial substrate for cofactor regeneration. Nevertheless, the use of catalytic amounts of cofactor with GDH/glucose, somehow, worsened conversion and stereoselectivity. Additionally, the asymmetric carboncarbon double bond reduction of some classes of $\alpha, \beta$-unsaturated esters is not applicable. For instance, $\alpha$-substituted cinnamic acid methyl esters bearing an additional $\alpha$-cyano moiety decomposed or polymerized under the reaction conditions for the enzymatic reduction. ${ }^{33}$ In this work, we conceived an alternative approach that has general applicability to directly access optically active $\alpha$-substituted carboxylic acids (Scheme 1). The approach combines two enzyme classes, namely ERs and aldehyde dehydrogenases (Ald-DHs), in a concurrent reductive-oxidative biocatalytic cascade. ${ }^{6}$

This strategy has several advantages: (I) the starting material is an $\alpha$-substituted $\alpha, \beta$-unsaturated aldehyde, a class of compounds extremely reactive for the carbon-carbon double bond reduction; (II) no external source of hydride from

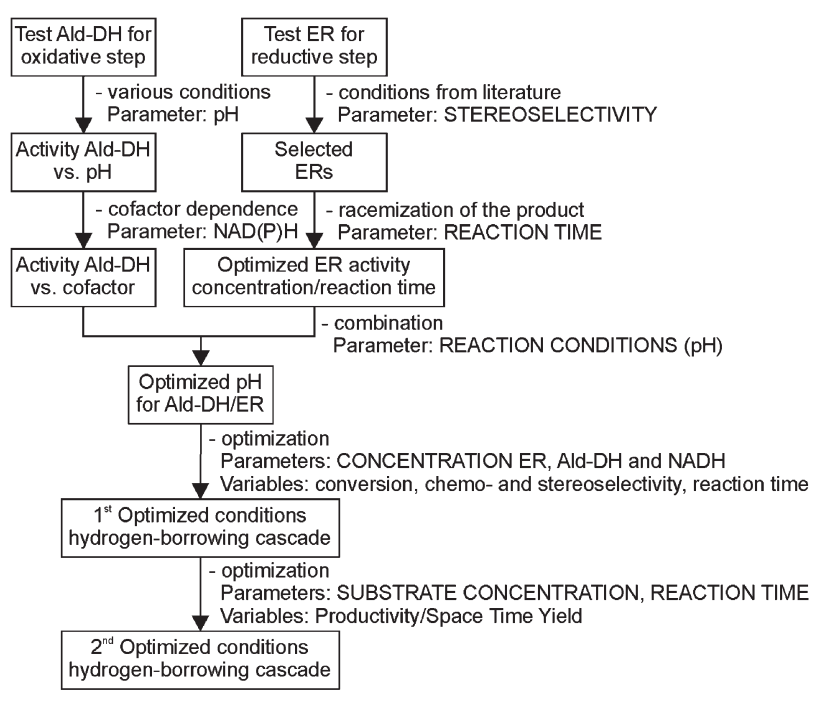

Chart 1 Systematic steps for designing a successful hydrogen-borrowing cascade reaction. 
a sacrificial substrate (e.g. glucose, formate) is required; (III) the cascade reaction has the highest atom efficiency as the only additional reagent is water and no waste is produced; (IV) the process takes advantage of the intrinsic stereoselectivity of the ER to enable transfer of the hydride predominantly onto one of the prochiral faces of the alkene moiety.

This challenging two enzyme hydrogen-borrowing cascade was developed following the systematic strategy as depicted in Chart 1. Finally, the potential utility of this cascade sequence was demonstrated in the production of diverse important intermediates for the chemical industry such as chiral substituted hydrocinnamic acids, aliphatic acids, heterocycles and even acetylated amino acids.

\section{Results and discussion}

Since the stereogenic centre is introduced into the final product in the first reductive step of the cascade (Scheme 2), we initially tested a wide panel of eleven different ERs that are originated from various sources such as bacteria, yeasts and plants. ${ }^{3-42}$ The parameter for this initial screening of the ERs was the stereoselectivity for the reduction of the carboncarbon double bond of the target substrate $\alpha$-methyl-transcinnamaldehyde (1a) (Chart 1). The starting reaction conditions were taken from a survey of the recent literature. ${ }^{21,35,43,44}$

Asymmetric reduction is commonly conducted using NADPH as cofactor that is recycled by glucose dehydrogenase (GDH) at the expense of glucose as the sacrificial co-substrate. Surprisingly, although it is known that $\alpha$-chiral aldehydes are prone to racemization in aqueous solution, ${ }^{45}$ the majority of the procedures reported in the literature for this biocatalytic reaction envisage $24 \mathrm{~h}$ reaction time. Therefore these reaction conditions and this reaction time were employed in the initial experiment. Quantitative conversion was achieved with the ERs tested, with XenA being the only exception (Table 1). However, the reduced aldehyde $(\mathbf{1 b})$ was obtained either in a racemic form or with poor enantiomeric excess (up to $28 \%(S)$ ). Moreover, a relevant amount of $\mathbf{1 b}$ (from $7 \%$ to $29 \%$ ) was further reduced to the corresponding alcohol (1c).

In order to ascertain the origin of the poor enantiomeric excess, biocatalytic reduction was studied in more detail using two selected ERs. OYE2 was chosen since it showed the highest ee $(28 \%(S))$ and better chemoselectivity compared to OYE3. YqjM was also selected because it shows high chemoselectivity (89\%), although the product was obtained in racemic form. In this experiment, the impact of the reaction time was evaluated on the conversion and ee. Additionally, NADPH was used in stoichiometric amount (i.e. without a recycling system) to avoid any possible cross-activity from GDH.

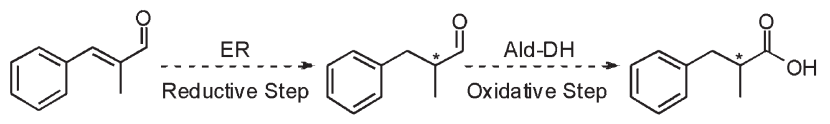

Scheme 2 Hydrogen borrowing cascade reaction.
Table 1 Asymmetric bioreduction of 1a using OYEs

\begin{tabular}{llllll}
\hline Entry & ER & Conv. $^{a}[\%]$ & $\mathbf{1 b}[\%]$ & $\mathbf{1 c}[\%]$ & ee $\mathbf{1 b}^{b}[\%]$ \\
\hline 1 & PETNR & $>99^{c}$ & 78 & 22 & $\mathrm{rac}$ \\
2 & TOYE & $>99^{c}$ & 87 & 13 & $\mathrm{rac}$ \\
3 & OYE2 & $>99^{c}$ & 75 & 25 & $28(S)$ \\
4 & OYE3 & $>99^{c}$ & 71 & 29 & $28(S)$ \\
5 & XenA & $66^{c}$ & 56 & 10 & $18(R)$ \\
6 & XenB & $>99^{c}$ & 82 & 18 & $\mathrm{rac}$ \\
7 & LeOPR1 & $>99^{c}$ & 85 & 15 & $\mathrm{rac}$ \\
8 & NerA & $>99^{c}$ & 79 & 21 & $\mathrm{rac}$ \\
9 & GluOx & $>99^{c}$ & 71 & 29 & $18(S)$ \\
10 & YqjM & $>99^{d}$ & 89 & 11 & $\mathrm{rac}$ \\
11 & MR & $>99^{d}$ & 93 & 7 & $\mathrm{rac}$
\end{tabular}

${ }^{a}$ Achiral GC (DB-Wax). ${ }^{b}$ Chiral HPLC (Chiralsil OJ-H). ${ }^{c}$ Reaction time $24 \mathrm{~h} .{ }^{d}$ Reaction time 6 h. Experimental conditions: reaction volume $=$

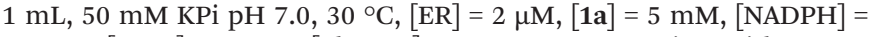
$10 \mu \mathrm{M},[\mathrm{GDH}]=10 \mathrm{U}$, [glucose] $=300 \mathrm{mM}$; extraction with MTBE $(2 \times 500 \mu \mathrm{L})$.

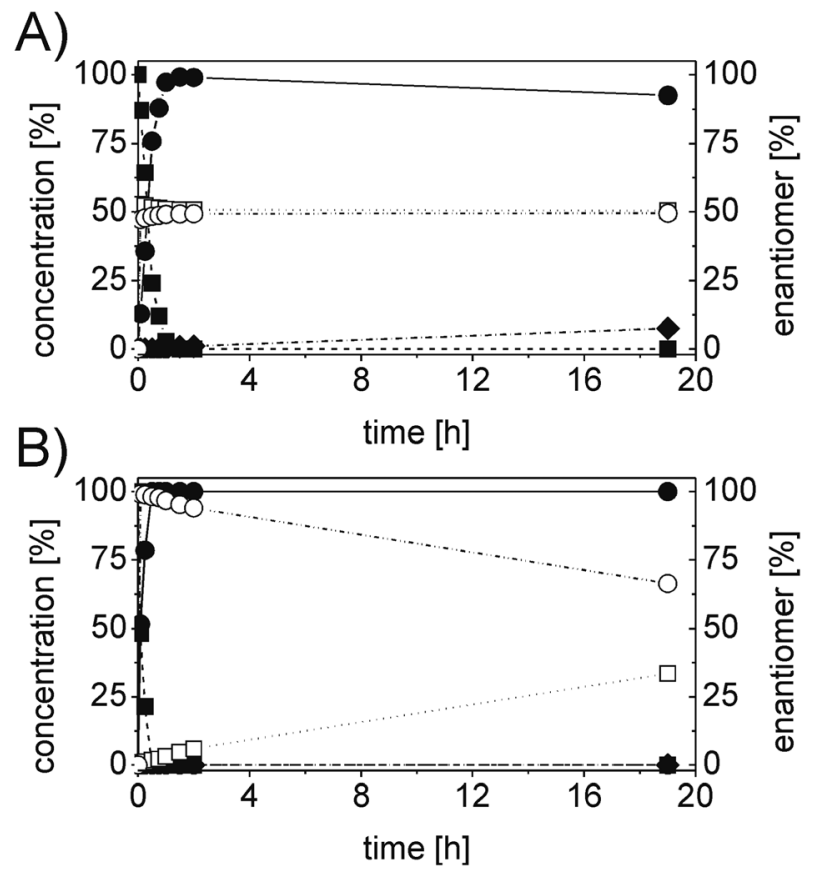

Fig. 1 Progress curve for the biotransformation of 1a by (A) YqjM and (B) OYE2. Concentration of $\alpha$-methyl-trans-cinnamaldehyde 1a ( $\square$ ), $\alpha$-methylhydro-cinnamaldehyde $1 \mathrm{~b}(\bullet), \alpha$-methylhydrocinnamic alcohol 1c $(\checkmark)$ and $(R)$ - $\alpha$-methyl-hydrocinnamaldehyde $(\square)$ and (S)- $\alpha$-methylhydro-cinnamaldehyde $(O)$. Experimental conditions: reaction volume $=$

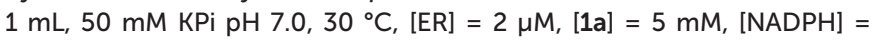
$11 \mathrm{mM}$; extraction with MTBE $(2 \times 500 \mu \mathrm{L})$. Conversion measured by achiral GC (DB-Wax); ee measured by chiral HPLC (Chiralsil OJ-H).

Fig. 1 shows that the reduction of the alkene moiety is complete after two hours using YqjM (Fig. 1A) and in less than 30 min using OYE2 (Fig. 1B). OYE2 performs the reduction of the carbon-carbon double bond with perfect stereoselectivity as witnessed by the ee of $>99 \%$ after the first few minutes of the reaction. Hence, the origin of the poor enantioselectivity for the reduction with OYE2 stems from the spontaneous chemical racemization of $\mathbf{1 b}$ in aqueous buffer. Furthermore, 
as the reaction is essentially complete after $15 \mathrm{~min}$, prolonging the reaction time is not advantageous as this depletes the ee of $\mathbf{1 b}$. In contrast, the optical purity of $\mathbf{1 b}$ was found to be extremely poor at early time points when the reduction was carried out with YqjM.

In another experiment, the same reaction under the same reaction conditions was repeated using catalytic NADPH and GDH/glucose for cofactor regeneration (Fig. S3 ESI †). In contrast to the experiment using OYE2 with stoichiometric NADPH, the use of catalytic NADPH in presence of GDH led to the formation of the alcohol $1 \mathrm{c}$ as side-product in significant amounts $(22 \%$ after $11 \mathrm{~h})$. Therefore ERs must be in general chemoselective enzymes for the reduction of 1a; further reduction to $1 \mathrm{c}$ is attributed to a promiscuous activity of the GDH (a few purified GDHs were tested). The reduction with stoichiometric NADPH and YqjM also led to the formation of a minor quantity of alcohol 1c (8\%) after $19 \mathrm{~h}$. However, this is attributed to the presence of some impurities (e.g. alcohol dehydrogenases) in the YqjM protein solution (Fig. S1 ESI†). Therefore, it is important to avoid the use of GDH and employ highly purified ERs to carry out biocatalytic reduction of substrate 1a. Even taking this into account one step reduction does not lead to high conversion and ee, because of spontaneous chemical racemization. The hydrogen-borrowing approach described here also has the advantage of solving this problem, since the aldehyde $\mathbf{1 b}$ is promptly oxidized to the corresponding non-enolisable acid $\mathbf{1 d}$.

The second branch of Chart 1 relates to the oxidative step catalyzed by an Ald-DH. The oxidation of $\mathbf{1 b}$ to the corresponding carboxylic acid (1d) was performed using three different aldehyde dehydrogenases, namely the Ald-DHs from bovine lens (Ald-DH-BOV), ${ }^{46,47}$ horse liver (Ald-DH-HL) ${ }^{48,49}$ and E. coli (Ald-DH-EC). ${ }^{50}$ The enzymes were tested for the conversion of $\mathbf{1 b}$. The parameters explored experimentally (Chart 1) were reaction pH values (step 1) and the requirement for a cofactor $\mathrm{NADP}^{+} / \mathrm{NAD}^{+}$(step 2). Ald-DH-BOV and Ald-DH-HL were shown to be strictly selective for $\mathrm{NAD}^{+}$; no conversion was observed with $\mathrm{NADP}^{+}$as cofactor (Table 2, entries 2 and 4; Table S2 ESI $\dagger$ for detailed time study). Conversely, Ald-DH-EC is able to accept both cofactors but the reaction proceeded faster with $\mathrm{NAD}^{+}$(Table 2, entries 5 and 6).

Table 2 Conversion of $1 \mathrm{~b}$ to $1 \mathrm{~d}$ after $23 \mathrm{~h}$ reaction time

\begin{tabular}{lllllll}
\hline Entry & Ald-DH & Cofactor & pH 6 & pH 7 & pH 8 & pH 9 \\
\hline 1 & BOV & NAD $^{+}$ & $20 \%$ & $52 \%$ & $63 \%$ & $74 \%$ \\
2 & BOV & NADP $^{+}$ & n.m. & n.m. & n.m. & n.m. \\
3 & HL & NAD $^{+}$ & $7 \%$ & $32 \%$ & $32 \%$ & $51 \%$ \\
4 & HL & NADP $^{+}$ & n.m. & n.m. & n.m. & n.m. \\
5 & EC & NAD $^{+}$ & $7 \%$ & $>99 \%$ & $>99 \%$ & $>99 \%$ \\
6 & EC & NADP $^{+}$ & $3 \%$ & $44 \%$ & $66 \%$ & $70 \%$
\end{tabular}

${ }^{a}$ n.m. not measurable. Experimental conditions: reaction volume $=$ $1 \mathrm{~mL}, 50 \mathrm{mM} \mathrm{KPi} \mathrm{(pH} \mathrm{6.0,} \mathrm{7.0,} \mathrm{8.0)} \mathrm{and} 50 \mathrm{mM}$ Tris/HCl pH 9.0, $30{ }^{\circ} \mathrm{C}$, reaction time $=23 \mathrm{~h},[$ Ald-DH $]=2 \mu \mathrm{M},[1 \mathbf{b}]=5 \mathrm{mM},\left[\mathrm{NAD}^{+}\right]=7 \mathrm{mM}$; extraction with MTBE $(2 \times 400 \mu \mathrm{L})$, derivatization with (trimethylsilyl) diazomethane to methylester. Conversion measured by achiral GC (DB-Wax).
Table $31 \mathrm{~h}$ bioreduction of $1 \mathrm{a}$ using NADH as cofactor

\begin{tabular}{|c|c|c|c|c|c|c|}
\hline \multirow{2}{*}{ Entry } & \multirow[b]{2}{*}{ ER } & \multicolumn{2}{|l|}{ pH 7} & \multicolumn{2}{|l|}{ pH 8} & \multirow{2}{*}{$\begin{array}{l}\text { pH } 9 \\
\text { Conv. } \\
{[\%]}\end{array}$} \\
\hline & & $\begin{array}{l}\text { Conv. }^{a} \\
{[\%]}\end{array}$ & $\begin{array}{l}\mathrm{ee}^{b} \\
{[\%]}\end{array}$ & $\begin{array}{l}\text { Conv. }^{a} \\
{[\%]}\end{array}$ & $\begin{array}{l}\mathrm{ee}^{b} \\
{[\%]}\end{array}$ & \\
\hline 1 & PETNR & 2 & n.d. & 2 & n.d. & n.m. \\
\hline 2 & TOYE & 50 & $16(S)$ & 32 & $\mathrm{rac}$ & n.m. \\
\hline 3 & OYE2 & 99 & $90(S)$ & 48 & $83(S)$ & n.m. \\
\hline 4 & OYE3 & 15 & $97(S)$ & 9 & $95(S)$ & n.m. \\
\hline 5 & XenA & 6 & n.d. & 5 & n.d. & n.m. \\
\hline 6 & XenB & 7 & n.d. & 4 & n.d. & n.m. \\
\hline 7 & LeOPR1 & 19 & $19(R)$ & 12 & $38(R)$ & n.m. \\
\hline 8 & NerA & 46 & $7(R)$ & 47 & $14(R)$ & n.m. \\
\hline 9 & GluOx & 19 & $50(S)$ & 12 & $39(S)$ & n.m. \\
\hline 10 & YqjM & 29 & $16(R)$ & 32 & $38(R)$ & n.m. \\
\hline 11 & MR & 78 & $5(R)$ & 71 & $8(R)$ & n.m. \\
\hline
\end{tabular}

${ }^{a}$ Achiral GC (DB-Wax). ${ }^{b}$ Chiral HPLC (Chiralsil OJ-H); n.d. not determined; n.m. not measurable. Experimental conditions: reaction volume $=1 \mathrm{~mL}, 50 \mathrm{mM} \mathrm{KPi}(\mathrm{pH} 7.0$ and 8.0$)$ and $50 \mathrm{mM}$ Tris/HCl $\mathrm{pH}$ $9.0,30{ }^{\circ} \mathrm{C},[\mathrm{ER}]=2 \mu \mathrm{M},[\mathbf{1 a}]=5 \mathrm{mM},[\mathrm{NADH}]=10 \mu \mathrm{M},[\mathrm{GDH}]=10 \mathrm{U}$, [glucose] $=300 \mathrm{mM}$; extraction with MTBE $(2 \times 500 \mu \mathrm{L})$.

Table 2 clearly shows that the reaction rate for Ald-DH-BOV as well as Ald-DH-HL gradually increases passing from $\mathrm{pH}$ 6, 7, 8 and reaching the maximum at $\mathrm{pH}$ 9. Moreover, Ald-DH-EC is active at a broader $\mathrm{pH}$ range. Also at $\mathrm{pH} 7$ - which is the preferred $\mathrm{pH}$ value for ERs - an acceptable reaction rate could be observed.

In the next step (Chart 1) the activity of the ERs was reanalyzed at different $\mathrm{pH}$ values and using NADH as cofactor, as this is the preferred cofactor for the Ald-DHs. This step is vital for the set-up of a successful hydrogen-borrowing cascade, as it aims at identifying suitable conditions for the combination of both enzyme classes. The reaction time was set to $1 \mathrm{~h}$ to minimize chemical racemization (Table 3). In all the cases at pH 9 no activity for the ERs could be measured. Only at pH 7, using OYE2 was possible to achieve quantitative conversion and a good enantiomeric excess (90\% (S); Table 3, entry 3). All the other ERs showed imperfect ee and/or low conversion under these reaction conditions. Unfortunately, none of the ERs tested could provide the $(R)$ enantiomer in high enantioenriched form. As a consequence OYE2 was selected as the best ER and the Ald-DH from E. coli as the best dehydrogenase for performing the cascade reaction.

Moving along Chart 1, the further steps are aimed at optimizing the cascade to maximize conversion, chemo- and stereoselectivity and reducing the reaction time. The parameters investigated are the concentrations of the enzymes and of the cofactor. The first combination of both enzymes - ER and Ald-DH - was performed with the optimized conditions identified in the single experiments $([$ OYE2 $]=[$ Ald-DH-EC $]=$ $2 \mu \mathrm{M},[\mathrm{NADH}]=10 \mu \mathrm{M})$. Unfortunately, after $6 \mathrm{~h}$ reaction time, the conversion was only $45 \%$ (Fig. 2 and Table S3 ESI†).

Nevertheless we noted that the Ald-DH preferred to oxidize the saturated aldehyde $\mathbf{1 b}$, rather than the unsaturated starting material 1a, as the main product was $\alpha$-methyl-hydro cinnamic acid (1d). Based on these results, the object parameters 


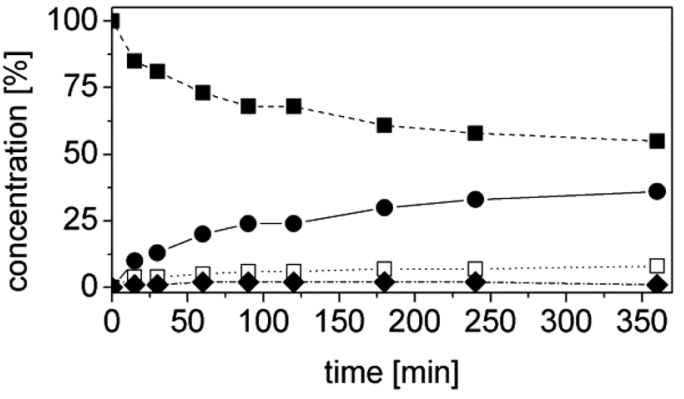

Fig. 2 First experiment one-pot two enzyme cascade reaction for the conversion of $1 \mathrm{a}$ to $1 \mathrm{~d}$. Concentration of $\alpha$-methylcinnamaldehyde $1 \mathrm{a}$ $(\square), \alpha$-methylhydrocinnamic acid $1 \mathrm{~d}(\bullet), \alpha$-methylhydrocinnamaldehyde 1b ( $\diamond)$ and $\alpha$-methylcinnamic acid $1 \mathrm{e}(\square)$. Experimental conditions: reac-

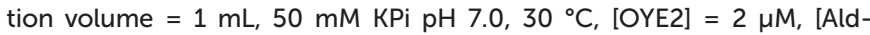
$\mathrm{DH}-\mathrm{EC}]=2 \mu \mathrm{M},[1 \mathrm{a}]=5 \mathrm{mM},[\mathrm{NADH}]=10 \mu \mathrm{M}$; two-step selective extraction with MTBE: (I) under basic conditions (aldehydes) and (II) acidic conditions and derivatization with (trimethylsilyl)diazomethane (acids (ester)); IS = 2-phenylethanol. Conversion was measured by achiral GC (DB-Wax).

(ER, Ald-DH, $\mathrm{NAD}^{+}$concentration, time) were varied for improving the outcome of the cascade (Table 4). The reaction was stopped after 6 hours. The substrate was kept at $5 \mathrm{mM}$ concentration whereas: (I) the amount of the cofactor was increased and (II) the concentration of the two enzymes was varied to investigate the influence of the ratio [ER]/[Ald-DH]. The latter is a crucial point because the concentrations of the two enzymes have to be carefully balanced. In fact, the Ald-DH must quickly oxidize the saturated aldehyde to avoid racemization of the aldehyde product; also the Ald-DH must oxidize the

Table 4 Optimization of the one-pot two enzyme cascade reaction for the conversion of $1 a$

\begin{tabular}{llccllll}
\hline & & & & & & & \\
Entry & $\begin{array}{l}\text { NADH } \\
{[\mu \mathrm{M}]}\end{array}$ & $\begin{array}{c}\text { OYE2 } \\
{[\mu \mathrm{M}]}\end{array}$ & $\begin{array}{c}\text { Ald-DH } \\
\text { EC }[\mu \mathrm{M}]\end{array}$ & $\begin{array}{l}\text { Conv. }^{a} \\
{[\%]}\end{array}$ & $\begin{array}{l}\text { 1e } \\
{[\%]}\end{array}$ & $\begin{array}{l}\text { 1d } \\
{[\%]}\end{array}$ & $\begin{array}{l}\mathbf{1 d}^{b} \\
{[\%]}\end{array}$ \\
\hline 1 & 500 & 2 & 2 & $>99$ & 2 & 98 & 98 \\
2 & 500 & 2 & 10 & $>99$ & 6 & 94 & 98 \\
3 & 500 & 10 & 2 & $>99$ & 2 & 98 & 99 \\
4 & 500 & 10 & 10 & $>99$ & 4 & 96 & 99 \\
5 & 250 & 2 & 2 & $>99$ & 5 & 95 & 98 \\
6 & 250 & 2 & 10 & $>99$ & 7 & 93 & 98 \\
7 & 250 & 10 & 2 & $>99$ & 4 & 96 & 99 \\
8 & 250 & 10 & 10 & $>99$ & 6 & 94 & 99 \\
9 & 100 & 2 & 2 & 90 & 5 & 82 & 97 \\
10 & 100 & 2 & 10 & $>99$ & 6 & 94 & 98 \\
11 & 100 & 10 & 2 & $>99$ & 5 & 95 & 99 \\
12 & 100 & 10 & 10 & $>99$ & 6 & 94 & 99 \\
13 & 50 & 10 & 5 & $>99$ & 5 & 95 & 99 \\
14 & 25 & 10 & 5 & $>99$ & 5 & 95 & 99 \\
15 & 10 & 10 & 5 & $>99$ & 6 & 94 & 99 \\
16 & 10 & 2 & 2 & 45 & 8 & 36 & n.d.
\end{tabular}

${ }^{a}$ Achiral GC (DB-Wax). ${ }^{b}$ Chiral HPLC (Chiralsil OJ-3); n.d. = not determined. Experimental conditions: reaction volume $=1 \mathrm{~mL}, 50 \mathrm{mM}$

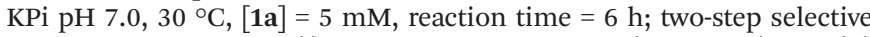
extraction with MTBE: (I) under basic conditions (aldehydes) and (II) acidic conditions and derivatization with (trimethylsilyl)diazomethane (acids (ester)); IS = 2-phenylethanol. saturated aldehyde intermediate $\mathbf{1 b}$, rather than the unsaturated starting material $\mathbf{1 a}$.

In almost all the cases quantitative conversion was achieved within $6 \mathrm{~h}$ reaction time. The only exceptions were when the concentration of both enzymes was reduced to $2 \mu \mathrm{M}$, using $10 \mu \mathrm{M}$ or $100 \mu \mathrm{M}$ NADH (Table 4, entries 9 and 16). The increased enzyme concentrations (up to $10 \mu \mathrm{M}$ for the ER and $5 \mu \mathrm{M}$ for the Ald-DH, respectively) afforded quantitative conversion, albeit only $10 \mu \mathrm{M}$ of NADH were employed (Table 4, entry 15). The ees were excellent in all the cases, ranging from $97 \%$ to $99 \%$. Therefore, the saturated aldehyde intermediate (1b) is quickly oxidized by the Ald-DH. It is also worth noting that very low quantities of the unsaturated carboxylic acid $\mathbf{1 e}$ were formed (from $2 \%$ to $8 \%$ ).

At this stage of the work we did not have any information regarding the kinetics of the process. Hence the progress of the reaction was monitored as a function of time. Specifically, the concentrations of the starting material (1a), of the intermediate (1b), of the final product (1d) and of the side product (1e) as well as the ees, were determined as a function of the time (Fig. 3). At this step of our work flow (Chart 1), the chemo- and, in particular, the stereoselectivity are maximized. In fact, the cascade reaction must run the minimum time required to achieve full conversion. Longer reaction times lead to lower ees, due to spontaneous racemization, and diminished productivity. For this experiment, the best conditions from the previous step were taken (Table 4, entry 14).

The reaction was extremely efficient since it was complete after $90 \mathrm{~min}$ despite the low concentrations of the enzymes used (Fig. 3, Table S4 ESI; $\dagger$ [OYE2] $=10 \mu \mathrm{M}$, [Ald-DH-EC] $=$ $5 \mu \mathrm{M})$. The concentration of the intermediate $\mathbf{1 b}$ remained constant with time ( $c a .3 \%)$. The cinnamic acid by-product $1 \mathrm{e}$ was mainly produced at the beginning of the reaction. This is not surprising as the cinnamic aldehyde $\mathbf{1 a}$ is present at

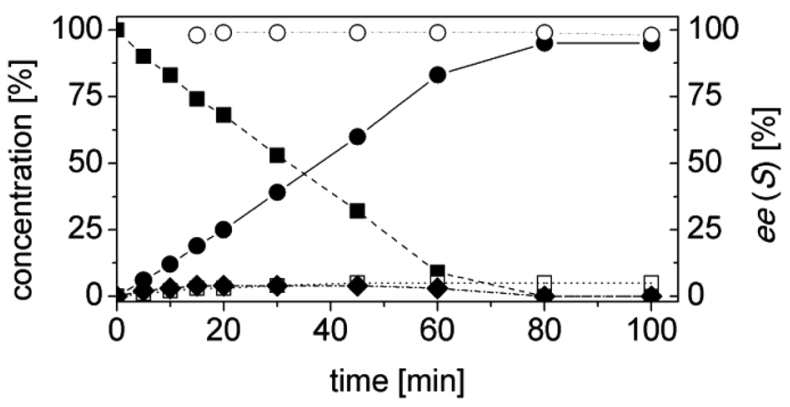

Fig. 3 Time study optimized one-pot two enzyme cascade reaction for the conversion of $1 \mathrm{a}$ to $1 \mathrm{~d}$. Concentration of $\alpha$-methylcinnamaldehyde 1a ( $\square), \alpha$-methylhydrocinnamic acid $1 \mathrm{~d}(\bullet), \alpha$-methylcinnamic acid 1e ( $\square$ ), $\alpha$-methylhydro-cinnamaldehyde $1 \mathrm{~b}(\boldsymbol{)})$ and enantiomeric excess of $\alpha$-methylhydrocinnamic acid (S)-1d (O). Experimental conditions: reac-

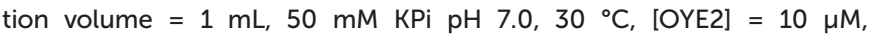
[Ald-DH-EC] $=5 \mu \mathrm{M},[\mathrm{NADH}]=25 \mu \mathrm{M},[1 \mathrm{a}]=5 \mathrm{mM}$; two-step selective extraction with MTBE: (I) under basic conditions (aldehydes) and (II) acidic conditions and derivatization with (trimethylsilyl)-diazomethane (acids (ester)); IS = 2-phenylethanol. Conversion was measured by achiral GC (DB-Wax) and ee by chiral HPLC (Chiralsil OJ-3). 
almost $5 \mathrm{mM}$ concentration, whereas the concentration of the intermediate $\mathbf{1 b}$ is almost negligible during the first few minutes of the reaction. However, after having identified the suitable reaction conditions, the concentration of cinnamic acid 1e remained constant during the reaction time and always below 5\%. This is an indication that the Ald-DH-EC is significantly more active towards the saturated aldehyde $\mathbf{1 b}$ rather than the unsaturated one $\mathbf{1 a}$, which is the crucial point for enabling this hydrogen-borrowing biocatalytic cascade reaction. Moreover, the cascade showed a perfect stereoselectivity (>99\% ee).

Productivity is an important factor for a successful process and this objective is considered in the last step of the proposed Chart 1. The studied parameter was the substrate concentration. Applying the optimized reaction conditions from the previous round and increasing the substrate concentration to $10 \mathrm{mM}, 97 \%$ conversion was still obtained after $6 \mathrm{~h}$ reaction time with high chemoselectivity (93\%) and excellent stereoselectivity (99\%; Table S5 ESI†). Increasing the substrate concentration up to $25 \mathrm{mM}$ required the prolongation of the reaction time up to $24 \mathrm{~h}$ and doubling of the amount of enzyme in order to achieve $>99 \%$ conversion (chemoselectivity $=96 \%$, ee $=96 \%$ ). However, bio-catalytic reductions with ERs are commonly performed at $5 \mathrm{mM}$ substrate concentration since these enzymes are plagued by substrate and/or product inhibition. ${ }^{51-53}$ The proposed two-step biocatalytic cascade we have developed here also allows alleviation of this problem because the product of the bioreduction (1b) is immediately removed by the Ald-DH in the second step.

The hydrogen-borrowing biocatalytic cascade was therefore successfully developed for the conversion of the test substrate 1a into 1d with quantitative conversion, improved productivity and excellent chemo- and stereoselectivity. Finally, we wanted to investigate if this strategy for developing a hydrogen-borrowing cascade has a more general validity and it is therefore applicable on a broad range of substrates. Thus, a panel of structurally diverse $\alpha, \beta$-unsaturated aldehydes, valuable synthons for the synthesis of chiral active pharmaceutical ingredients, were selected (Fig. 4).

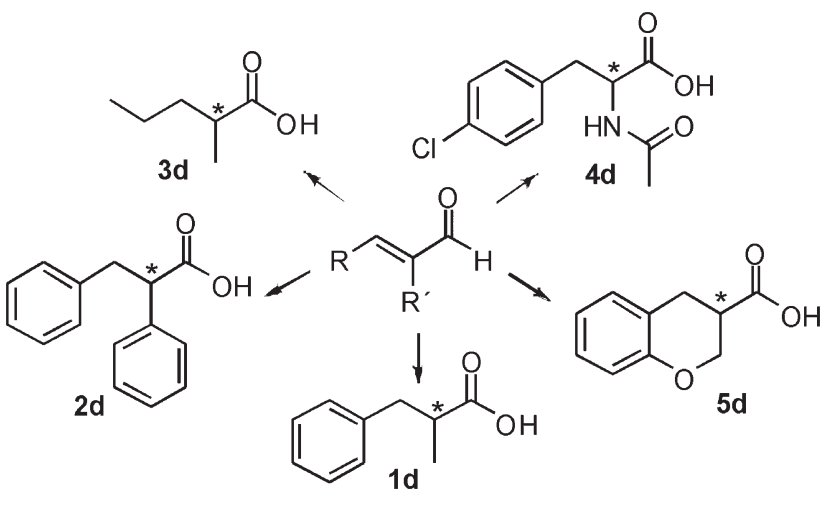

Fig. 4 Schematic view of the broad substrate scope applicability of the hydrogen-borrowing cascade combining ERs and Ald-DHs.
For example, enantiopure $\mathbf{1 d}$ is a precursor for the production of biological active compounds that possess muscle relaxant activity. ${ }^{54,55} \mathbf{2 d}$ constitutes the main core of drugs possessing antagonist activity for the acetylcholine M1 receptor of human. ${ }^{56} \mathbf{3 d}$ is commonly employed for the production of herbicidals, ${ }^{57}$ antibacterial $^{58}$ as well as anticancer compounds (e.g. leukemia, lung and prostate carcinoma). ${ }^{59-61}$ Optically active compound $\mathbf{5 d}$ and derivatives thereof are precursors of enantiopure aminochromane derivatives; these can be obtained through the conversion of the carboxylic moiety into the isocyanate intermediate, followed by Curtius rearrangement. The optically active aminochromanes are key intermediates of many antidepressant drugs such as robalzotan, ${ }^{62}$ ebalzotan $^{63}$ as well as DBH inhibitors such as chromanyl-imidazolethiones. ${ }^{64}$ Finally, our strategy can give access to enantioenriched unnatural amino acids. For instance $N$-acetylated $(S)$-para-chloro phenylalanine 4d was obtained. Through the carbon carbon coupling using the chloro group on the aromatic ring, more complex structures possessing various biological activities can be achieved. ${ }^{65-68}$ (S)-para-chloro phenylalanine derivatives also possess antimycobacterial (e.g. Mycobacterium tuberculosis), ${ }^{69}$ antifungal $^{70}$ as well as anticancer activity. ${ }^{71}$ Additionally, $N$-derivatized (S)-para-chloro phenylalanine is also used for the production of herbicides. ${ }^{72}$

For each substrate, the steps described in Chart 1 were applied as described for 1a. For instance, in the case of $\alpha$-phenylcinnamaldehyde (2a), two ERs, namely PETNR and XenB, showed the highest activity/stereoselectivity for the reduction of the carbon-carbon double bond of the unsaturated aldehyde; the Ald-DH from bovine lens was found to be the most efficient enzyme for the oxidation of the aldehyde intermediate (2b) to the corresponding acid (2d) (Table S6 and S7 ESI $\dagger$ ). Fig. 5 depicts the final time studies, after the overall procedure described in Chart 1 , for the conversion of $\mathbf{2 a}$ into $\mathbf{2 d}$ using PETNR and XenB in combination with the aldehyde dehydrogenase from bovine lens (Fig. 5A and B, and Table S8 and S9 ESI $\dagger$ for detailed information). Hence the substrate bearing the bulky phenyl-group in the alpha position was also accepted by PETNR and XenB with high stereoselectivity. In the hydrogen-borrowing cascade reaction using PETNR/Ald-DH-BOV, the conversion reached $92 \%$ after $4 \mathrm{~h}$, with $91 \%$ chemo-selectivity and a perfect ee (97\%). The combination of XenB/Ald-DH-BOV resulted in $91 \%$ conversion after $5 \mathrm{~h}$ (95\% chemoselectivity) and excellent ee of $99 \%$. Further changes on the reaction conditions (e.g. concentration of $\mathrm{NADH}$ and AldDH) did not improve the chemoselectivity but had a negative impact on the stereoselectivity (Table S10 ESI $\dagger$ ).

Using trans-2-methyl-2-pentenal (3a) as substrate, OYE2 and Ald-DH-EC were selected as the best performing ER and Ald-DH, respectively (Table S11 and S12 ESI $\dagger$ ). Fig. 6 (Table S13 $\left.\mathrm{ESI}_{\dagger}^{\dagger}\right)$ displays the time study for the one-pot concurrent cascade reaction. Full conversion was obtained after $60 \mathrm{~min}$, showing an ee of $98 \%$. Using the Ald-DH from E. coli, 13\% of the unsaturated acid side product $3 \mathbf{e}$ were formed. Again, any change in the reaction condition resulted in the same chemoselectivity but lower ee (96\%). However, the chemoselectivity 
A)

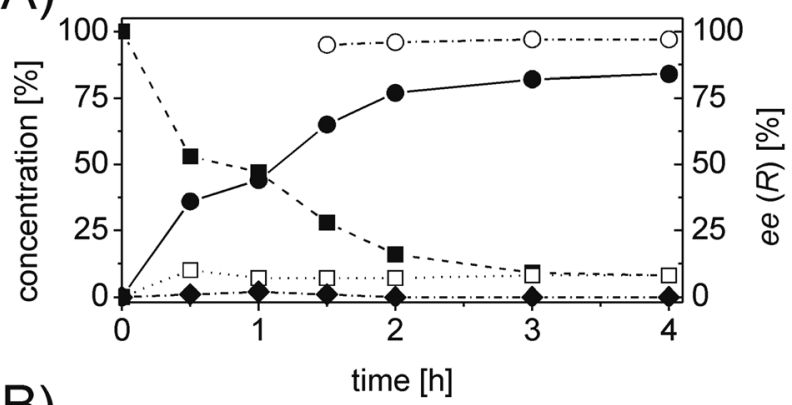

B)

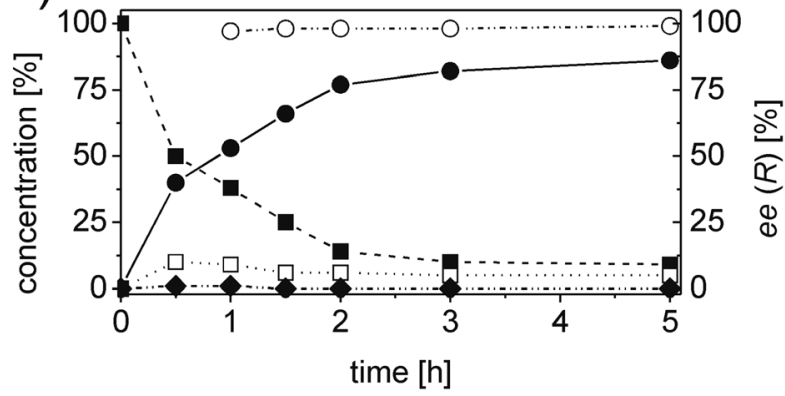

Fig. 5 Progress curves for the one-pot two enzyme cascade reaction of $2 a$ by (A) PETNR and Ald-DH-BOV and (B) XenB and Ald-DH-BOV. Concentration of $\alpha$-phenylcinnamaldehyde $2 a(\square), \alpha$-phenylhydrocinnamic acid 2d (๑), $\alpha$-phenyl-cinnamic acid 2e $(\square), \alpha$-phenylhydrocinnamaldehyde $2 \mathrm{~b}(\diamond)$ and enantiomeric excess of $\alpha$-phenylhydrocinnamic acid $(R)-2 d(O)$. Experimental conditions: reaction volume

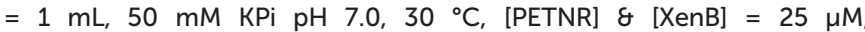
$[$ Ald-DH-BOV] $=4 \mu \mathrm{M},[\mathrm{NADH}]=50 \mu \mathrm{M},[2 \mathrm{a}]=5 \mathrm{mM}$; two-step selective extraction with MTBE: (I) under basic conditions (aldehydes) and (II) acidic conditions and derivatization with (trimethylsilyl)diazomethane (acids (ester)); IS = 2-phenylethanol. Conversion was measured by achiral GC (DB-Wax) and ee by chiral HPLC (Chiralsil OJ-3).

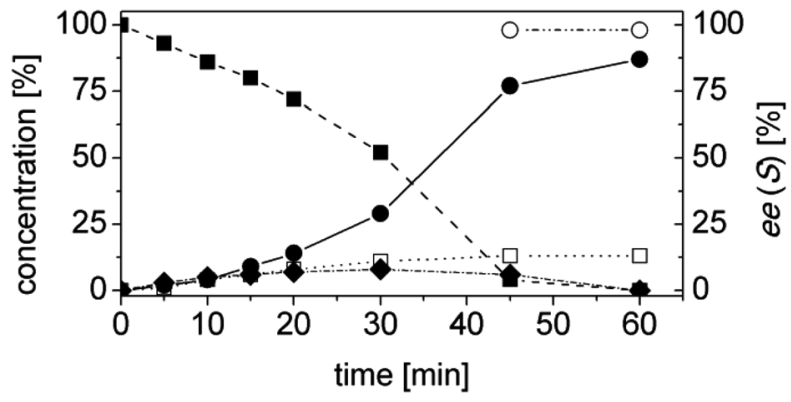

Fig. 6 Progress curves for the one-pot two enzyme cascade reaction of $3 a$ by OYE2 and Ald-DH-EC. Concentration of trans-2-methyl-2-pen-

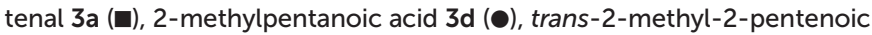
acid 3 e ( $\square$ ), 2-methyl-pentanal $3 b(\$)$ and enantiomeric excess of 2-methylpentanoic acid (S)-3d (O). Experimental conditions: reaction volume $=1 \mathrm{~mL}, 50 \mathrm{mM} \mathrm{KPi} \mathrm{pH} \mathrm{7.0,30}{ }^{\circ} \mathrm{C}$, [OYE2] $=10 \mu \mathrm{M}$, [Ald-DH-EC] $=3 \mu \mathrm{M},[\mathrm{NADH}]=25 \mu \mathrm{M},[3 \mathrm{a}]=5 \mathrm{mM}$; extraction with MTBE $(2 \times 400$ $\mu \mathrm{L})$ under acidic conditions and derivatization with (trimethylsilyl)-diazomethane to methylester. Conversion was measured by achiral GC (DB1701) and ee by chiral GC (Restek Rt-BDEXsm).

was improved (only 8-9\% of $3 \mathbf{c}$ were formed) when the Ald-DH from bovine lens (Ald-DH-BOV) was combined with OYE2 remaining the ee still perfect $(>98 \%$, Table S14 ESI†े).

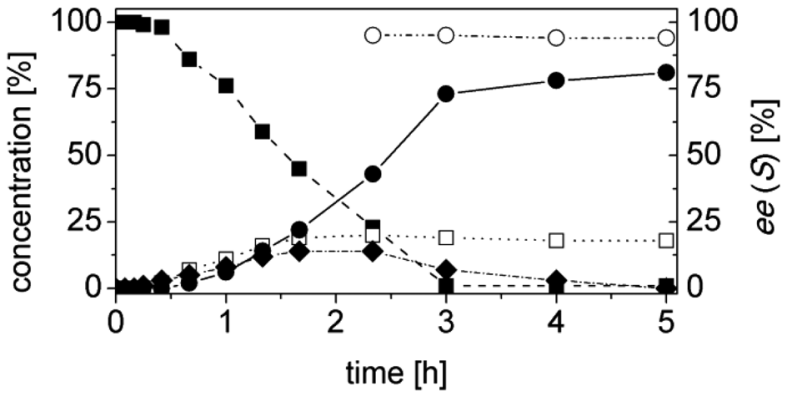

Fig. 7 Progress curves for the one-pot two enzyme cascade reaction of $4 a$ by OYE2 and Ald-DH-BOV. Concentration of (Z)-N-(1-(4-chlorophenyl)-3-oxoprop-1-en-2-yl)acetamide 4a ( $\square)$, 2-acetyl-4-chloroDL-phenylalanine 4d (๑), (Z)-2-acetamido-3-(4-chlorophenyl)acrylic acid 4e ( $\square$ ), $N$-(1-(4-chlorophenyl)-3-oxopropan-2-yl)acetamide 4b $(\diamond)$ and enantiomeric excess of 2-acetyl-4-chloro-L-phenyl-alanine (S)-4d (O). Experimental conditions: reaction volume $=1 \mathrm{~mL}, 50 \mathrm{mM} \mathrm{KPi} \mathrm{pH} \mathrm{7.0,}$ $30{ }^{\circ} \mathrm{C}$, [OYE2] $=10 \mu \mathrm{M},[$ Ald-DH-BOV] $=10 \mu \mathrm{M},[\mathrm{NADH}]=50 \mu \mathrm{M},[4 \mathrm{a}]=$ $5 \mathrm{mM}$; extraction under acidic conditions with EtOAc $(2 \times 400 \mu \mathrm{L})$ and derivatization with (trimethylsilyl)diazomethane to methylester. Conversion measured by achiral GC (HP5) and ee value by chiral GC (DEX-CB).

All three Ald-DHs have been tested for the oxidation of (Z)$N$-(1-(4-chlorophenyl)-3-oxoprop-1-en-2-yl)acetamide (4a) as well as the related saturated aldehyde $N$-(1-(4-chlorophenyl)-3oxopropan-2-yl)acetamide (4b) to the corresponding carboxylic acids. Two independent experiments showed that the Ald-DHs clearly preferred to oxidize the saturated substrate $(\mathbf{4 b})$; after $5 \mathrm{~h}$ reaction time as the conversion for $\mathbf{4 b}$ was much higher than for $4 a$ (Table S16 and S17 ESI†).

OYE2 and Ald-DH-BOV were combined for performing the cascade reaction starting from 4 a, yielding $99 \%$ conversion, $95 \%$ ee and $81 \%$ chemoselectivity after $3 \mathrm{~h}$ (Fig. 7, Table S20 ESI + ). Increasing the concentration of the Ald-DH from $10 \mu \mathrm{M}$ to $50 \mu \mathrm{M}$ slightly increased the chemoselectivity $(83 \%)$ and the ee value (96\%). In general, the ee was never higher than $96 \%$ since the few initial minutes of the reaction. Thus, for $\mathbf{4 a}$, the ee is limited by the intrinsic stereoselectivity of the ER (Table S21 ESI $\dagger$ ).

The last substrate investigated was $2 H$-chromene-3-carbaldehyde (5a). After $2 \mathrm{~h}$ reaction time, quantitative conversion was obtained for the one-pot two enzymes cascade reaction using OYE2 or GluOx in combination with Ald-DH-EC resulting in $81 \%$ chemoselectivity and $95 \%$ ee ( $S$-enantiomer, Fig. 8 , Table S25 and S26 ESI†).

The best results for the one-pot two-enzyme cascade reaction for substrates 1a-5a are summarized in Table 5. Although the substrates investigated are structurally diverse, a suitable adjustment of the reaction conditions allowed for obtaining quantitative conversion in four cases out of five. Chemoselectivity varied from good to excellent. Moreover, the chemoselectivity might be improved if other Ald-DHs will be discovered or engineered to accept only the saturated aldehyde intermediate. The stereoselectivity was also in general elevated, although there is an urgent demand for stereocomplementary ERs that would lead to the opposite enantiomer with equally high ees. 
A)
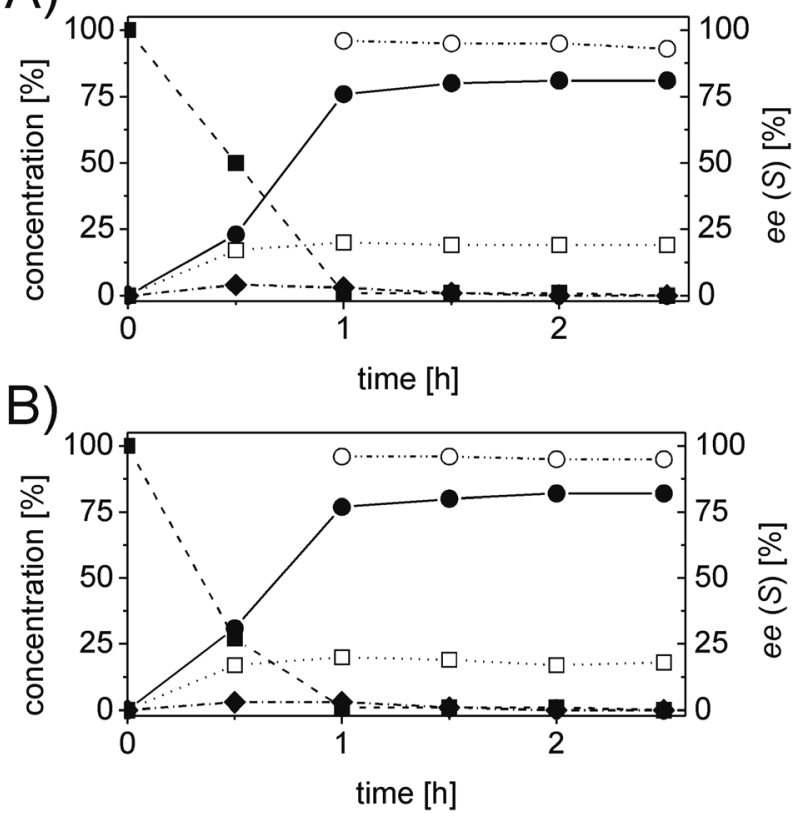

Fig. 8 Progress curves for the one-pot two enzyme cascade reaction of $5 a$ by (A) OYE2 and Ald-DH-EC and (B) GluOx and Ald-DH-EC. Concentration of $2 \mathrm{H}$-chromene-3-carbaldehyde $5 \mathrm{a}(\square), 3,4$-dihydro $2 \mathrm{H}$ benzopyran-3-carboxylic acid $\mathbf{5 d}(\bullet), 2 \mathrm{H}$-chromene-3-carboxylic acid $5 e(\square)$, chromane-3-carbaldehyde $5 b(\$)$ and enantiomeric excess of 3,4-Dihydro $2 \mathrm{H}$-benzopyran-3-carboxylic acid (S)-5d (O). Experimental

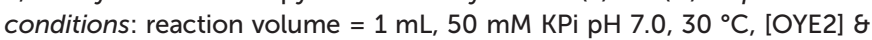
[GluOx] $=10 \mu \mathrm{M},[$ Ald-DH-EC] $=3 \mu \mathrm{M},[\mathrm{NADH}]=100 \mu \mathrm{M},[5 \mathrm{a}]=5 \mathrm{mM}$; extraction under acidic conditions with EtOAc $(2 \times 400 \mu \mathrm{L})$ and derivatization with (trimethylsilyl)diazomethane to methylester. Conversion measured by achiral GC (DB-Wax) and ee value by chiral GC (Restek Rt-ßDEXsm).
As previously mentioned, substrates 1a and 3a have been tested in a concomitant work by another group. ${ }^{12}$ It is important to point out that the overall strategy depicted in Chart 1 was not developed and the enzymes were simply mixed together without any additional accurate study. As a consequence, in this study, substrate 1a and 3a were indeed quantitatively converted but at the expense of the ees that were only $64 \%$ and $78 \%$, respectively. In contrast, our study demonstrates that it is possible to reach up to $99 \%$ stereoselectivity after selecting the best suitable ER and systematically tuning the reaction parameters (Table 5, entry 1 and 3). Additionally, our procedure generally allowed for reduction of the reaction time from $24 \mathrm{~h}$ to few hours. The substrate concentration was increased as well. Both factors lead to a dramatic increase of the productivity. Substrate 5a was instead the object of a two-step cascade combining ERs with alcohol dehydrogenases to give enantioenriched $\beta$-substituted alcohols. ${ }^{45}$ The alcohol was recovered with $91 \%$ ee, whereas in our study the related carboxylic acid was obtained with $95 \%$ ee (Table 5 , entry 5 ). Therefore, our proposed methodology allows one to obtain the highest chemoselectivity and ee for a given hydrogen-borrowing cascade.

Finally, 1d was produced on a preparative scale $(100 \mathrm{mg}$ of starting material 1a) resulting in quantitative conversion after $2 \mathrm{~h}$ reaction time with $96 \%$ chemoselectivity and $>98 \%$ ee $(S)$. After work-up, the isolated yield was $88 \%$.

\section{Materials and methods}

Synthesis of substrates and reference compounds, sources and cloning/expression/purification conditions for ERs and Ald-DHs used in this study, analytical methods as well as chiral GC and HPLC chromatograms can be found in the ESI. $\dagger$

Table 5 Summary results for the optimized one-pot two enzyme cascade reaction for the conversion of $5 \mathrm{mM}$ substrate

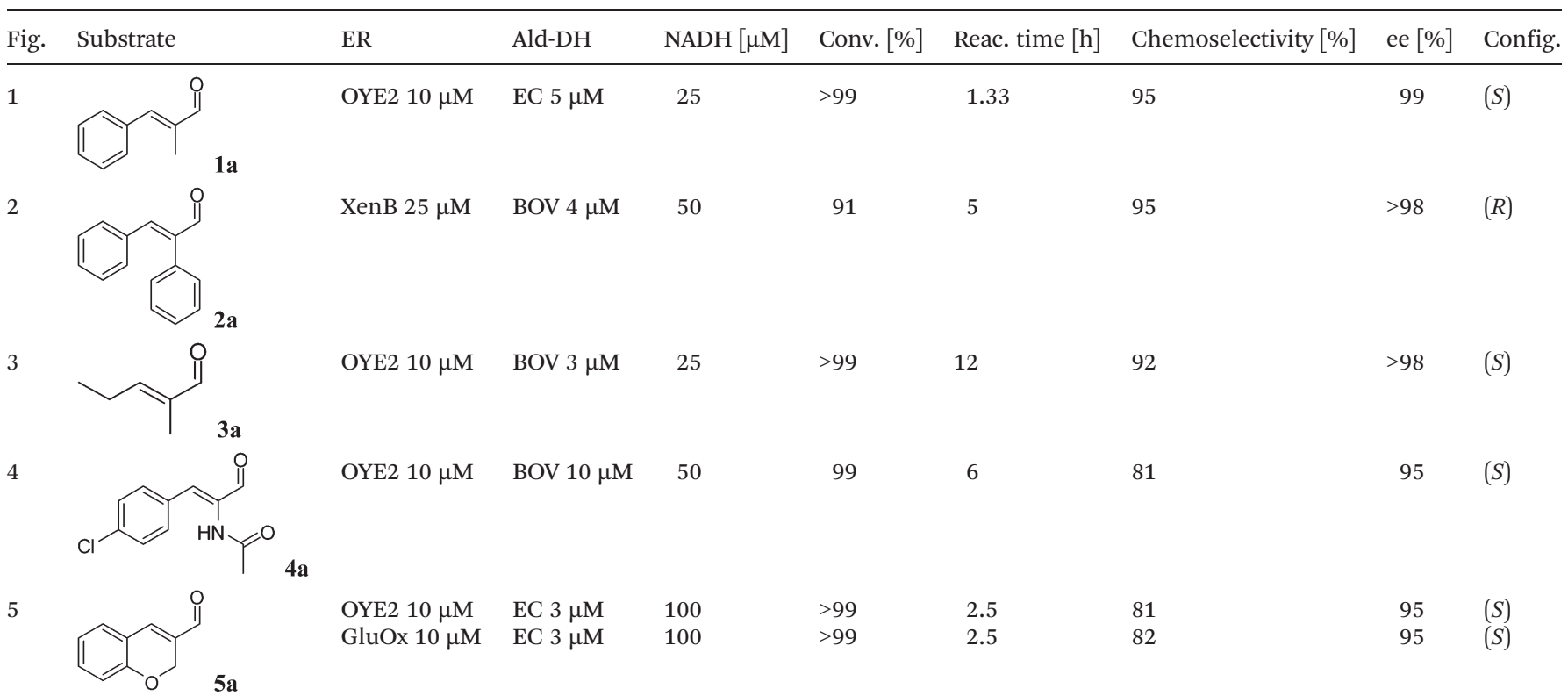




\section{Materials}

$\alpha$-Methyl-trans-cinnamaldehyde (1a), $\alpha$-methylhydrocinnamic acid (1d), $\alpha$-methylcinnamic acid (1e), $\alpha$-phenylhydrocinnamic acid (2d), $\alpha$-phenylcinnamic acid (2e), trans-2-methyl-2-pentenal (3a), 2-methylpentanal (3b), 2-methylpentanoic acid (3d), trans-2-methyl-2-pentenoic acid (3e), 2-acetyl-4-chloroDL-phenylalanine (4d), 3,4-dihydro $2 \mathrm{H}$-benzopyran-3-carboxylic acid (5d) and (trimethylsilyl)diazomethane (2 $\mathbf{M}$ in hexanes) were purchased from Sigma Aldrich (Gillingham, Dorset, UK). 2H-Chromene-3-carbaldehyde (5a) was purchased from Thermo Fisher Scientific (Loughborough, UK). Glucose dehydrogenase (GDH, CDX-901) was bought from Codexis (Redwood City, CA, USA). Synthetic genes for the Ald-DHs were bought from GenScript (Piscataway, NJ, USA).

$\alpha$-methylhydrocinnamaldehyde (1b), $\alpha$-methylhydrocinnamic alcohol (1c), $\alpha$-phenylcinnamaldehyde (2a), $\alpha$-phenylhydrocinnamaldehyde (2b), (Z)-N-(1-(4-chloro-phenyl)-3oxoprop-1-en-2-yl)acetamide (4a) and chromane-3-carbaldehyde (5b) were chemically synthesized as described in the ESI. $\dagger$

$N$-(1-(4-chlorophenyl)-3-oxopropan-2-yl)acetamide (4b) was obtained through a biotransformation of the related unsaturated substrate (4a) using ER and glucose as the final reducing reagent. (Z)-2-acetamido-3-(4-chloro-phenyl)-acrylic acid (4e) and $2 \mathrm{H}$-chromene-3-carboxylic acid (5e) were obtained through a biotransformation of the related substrates (4a and 5a, respectively) using Ald-DH and stoichiometric amounts of $\mathrm{NAD}^{+}$(see ESI $\dagger$ ).

\section{General procedure for biotransformations}

The substrates were dissolved as stock solutions in ethanol or DMSO, and then diluted to $5 \mathrm{mM}$ in the reaction ( $2 \%$ final cosolvent concentration). Standard reactions $(1.0 \mathrm{~mL})$ were performed in phosphate buffer (50 mM KH2PO4/K2HPO4, $\mathrm{pH}$ 7.0) and reactions were shaken at $30^{\circ} \mathrm{C}$ at $160 \mathrm{rpm}$ in an orbital shaker. The reaction was terminated by the extraction with EtOAc or MTBE $(2 \times 500 \mu \mathrm{L})$ under acidic conditions, the extracts were dried using anhydrous $\mathrm{MgSO} 4$ and analyzed by GC or HPLC as described in the ESI $\dagger$ to determine the conversion and enantiomeric excess. (I) Asymmetric bioreduction using ERs: $1 \mathrm{~mL}$ reaction volume consisted of aldehydes $\mathbf{1 a}$ to $\mathbf{5 a}$ ( $5 \mathrm{mM})$, ER (2 to $4 \mu \mathrm{M})$, NAD(P)H $(11 \mathrm{mM})$. If the GDH recycling system was applied, the reaction mixture consisted of $\mathrm{NAD}(\mathrm{P}) \mathrm{H}(10 \mu \mathrm{M})$, glucose $(15 \mathrm{mM})$, and GDH (10 U). (II) Oxidation of aldehydes using Ald-DHs: The reaction mixture consisted of substrate $\mathbf{1 b}$ to $5 \mathbf{b}(5 \mathrm{mM})$, Ald-DH $(2$ to $5 \mu \mathrm{M})$ and $\mathrm{NAD}(\mathrm{P})^{+}$( 6 to $\left.7 \mathrm{mM}\right)$. After extraction with MTBE or EtOAc $(2 \times$ $400 \mu \mathrm{L}$ ) under acidic conditions and drying with anhydrous $\mathrm{MgSO}_{4}$, the carboxylic acids were derivatized to the corresponding methylester and analyzed by GC or HPLC. (III) Onepot two enzyme cascade reaction: $1 \mathrm{~mL}$ reaction mixture consisted of substrate (1a to 5a, $5 \mathrm{mM})$, ER $(2-25 \mu \mathrm{M})$, Ald-DH $(2-10 \mu \mathrm{M})$ and cofactor NADH $(10-500 \mu \mathrm{M})$. A two-step extraction protocol was performed, extracting the aldehydes under basic conditions with MTBE or EtOAc $(2 \times 500 \mu \mathrm{L})$ and in a second step the carboxylic acids under acidic conditions $(2 \times$ $400 \mu \mathrm{L}$ MTBE or EtOAc). The acids were derivatized using the protocol described below.

\section{Derivatization of carboxylic acids to methylester}

To the extracts $(800 \mu \mathrm{L}) \mathrm{MeOH}(200 \mu \mathrm{L})$ and (trimethylsilyl)diazomethane $(10 \mu \mathrm{L})$ were added and the reaction was shaken at $30{ }^{\circ} \mathrm{C}, 160 \mathrm{rpm}$ for $60 \mathrm{~min}$. The excess of the derivatization reagent was destroyed by the addition of acetic acid $(2 \mu \mathrm{L})$ and the reaction was again shaken at $30{ }^{\circ} \mathrm{C}$ for another 25 min prior to analysis of the compounds by GC or HPLC.

\section{Conclusions}

In summary, we have developed a systematic strategy to set up an efficient two-step hydrogen-borrowing cascade in terms of conversion, chemoselectivity, stereoselectivity, reaction time and substrate concentration. The biocatalytic cascade possesses the highest atom efficiency since the hydride consumed in the first reductive step is produced in the following oxidative step. The only additional reagent is a water molecule and no waste (e.g. gluconolactone, carbon dioxide, etc.) is produced. This approach was applied to the conversion of $\alpha$-substituted $\alpha, \beta$-unsaturated aldehydes into the related optically active saturated carboxylic acids. Our methodology proved to be successful towards a panel of diverse substrates and can be applied for the production of chiral substituted cinnamic acids, aliphatic acids, heterocycles and even acetylated amino acids. Future work should aim at further improving the chemoselectivity by selecting or engineering other aldehyde dehydrogenases or reversing the stereoselective outcome of the reaction by engineering stereocomplementary enereductases.

\section{Abbreviations}

$\begin{array}{ll}\text { ER } & \text { Ene-reductase } \\ \text { Ald-DH } & \text { Aldehyde dehydrogenase }\end{array}$

\section{Acknowledgements}

The work was funded by the UK Biotechnology and Biological Sciences Research Council (BBSRC; BB/K0017802/1) and GlaxoSmithKline. N.S.S. received funding as an Engineering and Physical Sciences Research Council (EPSRC) Established Career Fellow (EP/J020192/1) and a Royal Society Wolfson Merit Award. F.G.M. has received funding from the European Union's Seventh Framework Programme FP7/2007-2013 under grant agreement no. 266025 (BIONEXGEN) and no. 115360 (CHEM21). Prof. Peter Macheroux (University of Technology, Graz) is gratefully acknowledged for providing the plasmid DNA for XenA, XenB and NerA, LeOPR1 and YqjM. 


\section{Notes and references}

1 R. A. Sheldon, I. W. C. E. Arends and U. Hanefeld, in Green Chemistry and Catalysis, Wiley-VCH Verlag $\mathrm{GmbH} \& \mathrm{Co}$. KGaA, 2007, pp. 1-47.

2 P. J. Dunn, Chem. Soc. Rev., 2012, 41, 1452-1461.

3 R. A. Sheldon, Chem. Soc. Rev., 2012, 41, 1437-1451.

4 E. Ricca, B. Brucher and J. H. Schrittwieser, Adv. Synth. Catal., 2011, 353, 2239-2262.

5 P. A. Santacoloma, G. Sin, K. V. Gernaey and J. M. Woodley, Org. Process Res. Dev., 2010, 15, 203-212.

6 J. H. Schrittwieser, J. Sattler, V. Resch, F. G. Mutti and W. Kroutil, Curr. Opin. Chem. Biol., 2011, 15, 249-256.

7 C. V. Voss, C. C. Gruber, K. Faber, T. Knaus, P. Macheroux and W. Kroutil, J. Am. Chem. Soc., 2008, 130, 13969-13972.

8 V. Köhler, Y. M. Wilson, M. Dürrenberger, D. Ghislieri, E. Churakova, T. Quinto, L. Knörr, D. Häussinger, F. Hollmann, N. J. Turner and T. R. Ward, Nat. Chem., 2013, 5, 93-99.

9 F. G. Mutti, A. Orthaber, J. H. Schrittwieser, J. G. de Vries, R. Pietschnig and W. Kroutil, Chem. Commun., 2010, 46, 8046-8048.

10 J. H. Sattler, M. Fuchs, K. Tauber, F. G. Mutti, K. Faber, J. Pfeffer, T. Haas and W. Kroutil, Angew. Chem., Int. Ed., 2012, 51, 9156-9159.

11 S. Gargiulo, D. J. Opperman, U. Hanefeld, I. W. C. E. Arends and F. Hollmann, Chem. Commun., 2012, 48, 6630-6632.

12 T. Winkler, H. Gröger and W. Hummel, ChemCatChem, 2014, 6, 961-964.

13 H. S. Toogood and N. S. Scrutton, Curr. Opin. Chem. Biol., 2014, 19, 107-115.

14 C. K. Winkler, G. Tasnadi, D. Clay, M. Hall and K. Faber, J. Biotechnol., 2012, 162, 381-389.

15 H. Toogood, D. Mansell, J. M. Gardiner and N. S. Scrutton, in Comprehensive Chirality, ed. N. J. Turner, 2012, vol. 1, pp. 216-255.

16 H. S. Toogood, J. M. Gardiner and N. S. Scrutton, ChemCatChem, 2010, 2, 892-914.

17 Y. Fu, K. Castiglione and D. Weuster-Botz, Biotechnol. Bioeng., 2013, 110, 1293-1301.

18 D. J. Mansell, H. S. Toogood, J. Waller, J. M. X. Hughes, C. W. Levy, J. M. Gardiner and N. S. Scrutton, Adv. Synth. Catal., 2013, 3, 370-379.

19 E. Burda, T. Ress, T. Winkler, C. Giese, X. Kostrov, T. Huber, W. Hummel and H. Groger, Angew. Chem., Int. Ed., 2013, 52, 9323-9326.

20 H. S. Toogood, A. Fryszkowska, V. Hare, K. Fisher, A. Roujeinikova, D. Leys, J. M. Gardiner, G. M. Stephens and N. S. Scrutton, Adv. Synth. Catal., 2008, 350, 2789-2803.

21 K. Durchschein, S. Wallner, P. Macheroux, W. Schwab, T. Winkler, W. Kreis and K. Faber, Eur. J. Org. Chem., 2012, 4963-4968.

22 Y. Yanto, H. H. Yu, M. Hall and A. S. Bommarius, Chem. Commun., 2010, 46, 8809-8811.
23 P. Ferraboschi, P. Grisenti, R. Casati, A. Fiecchi and E. Santaniello, J. Chem. Soc., Perkin Trans. 1, 1987, 17431748.

24 S. Koul, D. H. G. Crout, W. Errington and J. Tax, J. Chem. Soc., Perkin Trans. 1, 1995, 2969-2988.

25 M. Utaka, S. Konishi, A. Mizuoka, T. Ohkubo, T. Sakai, S. Tsuboi and A. Takeda, J. Org. Chem., 1989, 54, 49894992.

26 C. Stueckler, M. Hall, H. Ehammer, E. Pointner, W. Kroutil, P. Macheroux and K. Faber, Org. Lett., 2007, 9, 5409-5411.

27 E. Brenna, F. G. Gatti, A. Manfredi, D. Monti and F. Parmeggiani, Catal. Sci. Technol., 2013, 3, 1136-1146.

28 C. Stueckler, C. K. Winkler, M. Bonnekessel and K. Faber, Adv. Synth. Catal., 2010, 352, 2663-2666.

29 C. K. Winkler, D. Clay, N. G. Turrini, H. Lechner, W. Kroutil, S. Davies, S. Debarge, P. O’Neill, J. Steflik, M. Karmilowicz, J. W. Wong and K. Faber, Adv. Synth. Catal., 2014, 356, 1878-1882.

30 C. Stueckler, C. K. Winkler, M. Hall, B. Hauer, M. Bonnekessel, K. Zangger and K. Faber, Adv. Synth. Catal., 2011, 353, 1169-1173.

31 E. Brenna, G. Fronza, C. Fuganti, D. Monti and F. Parmeggiani, J. Mol. Catal. B: Enzym., 2011, 73, 17-21.

32 E. Brenna, F. G. Gatti, A. Manfredi, D. Monti and F. Parmeggiani, Org. Process Res. Dev., 2012, 16, 262-268.

33 G. Tasnadi, C. K. Winkler, D. Clay, N. Sultana, W. M. F. Fabian, M. Hall, K. Ditrich and K. Faber, Chem. Eur. J., 2012, 18, 10362-10367.

34 C. E. French and N. C. Bruce, Biochem. J., 1994, 301, 97103.

35 B. V. Adalbjornsson, H. S. Toogood, A. Fryszkowska, C. R. Pudney, T. A. Jowitt, D. Leys and N. S. Scrutton, ChemBioChem, 2010, 11, 197-207.

36 P. A. Karplus, K. M. Fox and V. Massey, FASEB J., 1995, 9, 1518-1526.

37 D. S. Blehert, B. G. Fox and G. H. Chambliss, J. Bacteriol., 1999, 181, 6254-6263.

38 J. Straßner, A. Fürholz, P. Macheroux, N. Amrhein and A. Schaller, J. Biol. Chem., 1999, 274, 35067-35073.

39 J. R. Snape, N. A. Walkley, A. P. Morby, S. Nicklin and G. F. White, J. Bacteriol., 1997, 179, 7796-7802.

40 N. Richter, H. Groger and W. Hummel, Appl. Microbiol. Biotechnol., 2011, 89, 79-89.

41 T. B. Fitzpatrick, N. Amrhein and P. Macheroux, J. Biol. Chem., 2003, 278, 19891-19897.

42 C. E. French, S. Nicklin and N. C. Bruce, J. Bacteriol., 1996, 178, 6623-6627.

43 A. Fryszkowska, H. Toogood, M. Sakuma, J. M. Gardiner, G. M. Stephens and N. S. Scrutton, Adv. Synth. Catal., 2009, 351, 2976-2990.

44 M. Hall, C. Stueckler, H. Ehammer, E. Pointner, G. Oberdorfer, K. Gruber, B. Hauer, R. Stuermer, W. Kroutil, P. Macheroux and K. Faber, Adv. Synth. Catal., 2008, 350, 411-418.

45 E. Brenna, F. G. Gatti, L. Malpezzi, D. Monti, F. Parmeggiani and A. Sacchetti, J. Org. Chem., 2013, 78, 4811-4822. 
46 H. H. Ting and M. J. Crabbe, Biochem. J., 1983, 215, 351-359.

47 H. H. Ting and M. J. Crabbe, Biochem. J., 1983, 215, 361368.

48 J. Eckfeldt, L. Mope, K. Takio and T. Yonetani, J. Biol. Chem., 1976, 251, 236-240.

49 J. H. Eckfeldt and T. Yonetani, Arch. Biochem. Biophys., 1976, 173, 273-281.

50 J. E. Jo, S. Mohan Raj, C. Rathnasingh, E. Selvakumar, W. C. Jung and S. Park, Appl. Microbiol. Biotechnol., 2008, 81, 51-60.

51 E. Brenna, F. G. Gatti, D. Monti, F. Parmeggiani and A. Sacchetti, Chem. Commun., 2012, 48, 79-81.

52 D. J. Bougioukou, A. Z. Walton and J. D. Stewart, Chem. Commun., 2010, 46, 8558-8560.

53 E. Brenna, F. G. Gatti, D. Monti, F. Parmeggiani and A. Sacchetti, ChemCatChem, 2012, 4, 653-659.

54 G. Maksay, E. Palosi, Z. Tegyey and L. Otvos, J. Med. Chem., 1981, 24, 499-502.

55 G. Maksay, Z. Tegyey, V. Kemeny, I. Lukovits, L. Otvos and E. Palosi, J. Med. Chem., 1979, 22, 1436-1443.

56 M. S. Poslusney, C. Sevel, T. J. Utley, T. M. Bridges, R. D. Morrison, N. R. Kett, D. J. Sheffler, C. M. Niswender, J. S. Daniels, P. J. Conn, C. W. Lindsley and M. R. Wood, Bioorg. Med. Chem. Lett., 2012, 22, 6923-6928.

57 N. B. Carter, L. M. D. Turnbull, P. J. Crowley and M. R. Cordingley, Syngenta Limited, WO2008/9908, 2008.

58 Z. Feng, J. H. Kim and S. F. Brady, J. Am. Chem. Soc., 2010, 132, 11902-11903.

59 B. Kongkathip, S. Akkarasamiyo, K. Hasitapan, P. Sittikul, N. Boonyalai and N. Kongkathip, Eur. J. Med. Chem., 2013, 60, 271-284.

60 H.-Y. Hung, E. Ohkoshi, M. Goto, K. F. Bastow, K. Nakagawa-Goto and K.-H. Lee, J. Med. Chem., 2012, 55, 5413-5424.
61 M. Reis, R. J. Ferreira, M. M. M. Santos, D. J. V. A. dos Santos, J. Molnár and M.-J. U. Ferreira, J. Med. Chem., 2013, 56, 748-760.

62 J. L. Evenden, E. M. Hammarberg, H. S. Hansson, S. E. Hellberg, L. G. Johansson, J. R. M. Lundkvist, S. B. Ross, D. D. Sohn and S. O. Thorberg, U.S. Patent 5616610, 1997.

63 H.-J. Federsel, Org. Process Res. Dev., 2000, 4, 362-369.

64 A. Beliaev, D. A. Learmonth and P. Soares-da-Silva, J. Med. Chem., 2006, 49, 1191-1197.

65 S. Kousteni, The Trustees of Columbia University in the city of New York, WO2013/74889, 2013.

66 M. D. Gershon and K. Margolis, Lexicon Pharmaceuticals, Inc., WO2013/148978, 2013.

67 G. Karsenty, P. F. Duciy, V. K. Yadav, D. Landry and S. X. Deng, The Trustees of Columbia University in the city of New York, WO2010/56992, 2010.

68 Q. Liu, Q. Yang, W. Sun, P. Vogel, W. Heydorn, X.-Q. Yu, Z. Hu, W. Yu, B. Jonas, R. Pineda, V. Calderon-Gay, M. Germann, E. O’Neill, R. Brommage, E. Cullinan, K. Platt, A. Wilson, D. Powell, A. Sands, B. Zambrowicz and Z.-c. Shi, J. Pharmacol. Exp. Ther., 2008, 325, 47-55.

69 E. C. Dykhuizen, J. F. May, A. Tongpenyai and L. L. Kiessling, J. Am. Chem. Soc., 2008, 130, 6706-6707.

70 K. Takiguchi, K. Yamada, M. Suzuki, K.-i. Nunami, K. Hayashi and K. Matsumoto, Agric. Biol. Chem., 1989, 53, 77-82.

71 T. Murata, M. Umeda, S. Yoshikawa, K. Urbahns, J. Gupta and O. Sakurai, Bayer Healthcare AG, WO2004/43926, 2004.

72 M. B. Aspinall, W. R. Mound, J. S. Wailes, W. G. Whittingham, J. Williams, C. L. Winn and P. A. Worthington, Syngenta Limited, WO2009/81112, 2009. 